\title{
The effect of number of convulsions per phase on the oscillation tendency
}

\author{
JOHN GAITO \\ York University, 4700 Keele Street, Downsview MSJ 1P3, Ontario, Canada
}

\begin{abstract}
Three groups of rats were subjected to a sequence of electrical stimulations alternating from one amygdala to the contralateral one. In Group 1 each stimulation was for one convulsion prior to stimulation of the opposite side. Rats in Group 2 had six convulsions per phase. Twelve convulsions per phase were provided for Group 3 rats. The oscillation tendency (high values for one side, low values for the other side) was prominent with all groups, but seemed less prevalent for the rats in the one convulsion per phase group.
\end{abstract}

The "kindling effect" has been investigated in a number of laboratories as a model of learning, a model of epilepsy, or as an example of behavioral change of interest in its own right (e.g., Gaito \& Gaito, 1974; Goddard, McIntyre, \& Leech, 1969). This event involves a change from normal exploration to automatic behaviors and, finally, to clonic convulsions in response to electrical stimulation of a specific brain site (e.g., amygdala).

In recent research in out laboratory using a sequence of alternating unilateral stimulations of the amygdala, an "oscillation effect" was observed (Gaito, 1976a). This oscillation usually consisted of low values for the amygdala first stimulated (primary site) and high values for the contralateral amygdala (secondary site). The effect was most prominent in latency data (number of seconds from onset of stimulation to onset of convulsion). Bilateral stimulation prior to the development of oscillation, or after it was prominent, produced little effect on this oscillation tendency (Gaito, 1976b), as did number of trials per day (one, three, six) (Gaito, 1976c). In the present experiment, the effect of number of convulsions per phase on the oscillation tendency was investigated.

\section{METHOD}

Twenty-seven male Wistar rats (approximately 135 days of age) were implanted bilaterally with bipolar electrodes in each amygdala. The brain coordinates for electrode implantation were the same as in previous experiments: $.5 \mathrm{~mm}$ posterior to bregma, $4.5 \mathrm{~mm}$ from midline, $8.5 \mathrm{~mm}$ from skull (interaural line was exactly $5 \mathrm{~mm}$ below the level of the upper incisor bar).

Seven or more days after surgery, brain stimulation began. Each rat in one group of nine (Group 1) was stimulated three times each day ( $1 \mathrm{~h}$ between trials) for $30 \mathrm{sec}$ with a $60-\mathrm{Hz}$ sine wave of 100 microA (peak to peak), using a Lafayette stimulator, until one convulsion resulted. The number of trials to reach this criterion was recorded, as was the latency and duration of this convulsion. On each trial, stimulation terminated after $30 \mathrm{sec}$ (if a convulsion was in progress or if no convulsion had occurred) or at the termination of the convulsion (if the convulsion ceased prior to $30 \mathrm{sec}$ ). On the day after a single convulsion, stimulation began at the secondary site and continued until one convulsion occurred. Then stimulation at the primary site was again instituted, etc. This sequential alternation of unilateral stimulation was continued for 10 phases. A second set of 10 phases was used only with this group.

In Group 2, nine rats were stimulated three times per day ( $1 \mathrm{~h}$ between trials) until six convulsions occurred in each of 10 alternating phases. In Group 3, nine rats had 12 convulsions for each of the 10 phases.

Some rats did not reach a clonic convulsion (CC) within 30 trials during Phases 1 and 2 . Then the intensity was slowly increased over trials until a CC occurred. A number of rats required 280-microA intensity; one did not convulse until 560 microA were used. The intensity required for a $\mathrm{CC}$ was maintained for the remaining phases.

\section{RESULTS}

The results for the three groups are shown in Table 1 for the two dependent variables over 10 phases: latency (number of seconds between onset of stimulation and onset of CC), criterion data [number of trials to $1 \mathrm{CC}$ (Group 1), 6 CCs (Group 2), or 12 CCs (Group 3)]. Duration of convulsion data were not analyzed because previous research (Gaito, 1976a) indicated few cases of oscillation in this dependent variable. As in previous work (Gaito, 1976a, b, c), an oscillation effect appeared which was stronger in latency than in criterion data. In the three groups, the numbers of oscillators in the latency data were five, seven, and six, respectively.

Table 1

Number of Rats Showing Oscillation (0) or No Oscillation (No) for the Three Groups Over 10 Phases

\begin{tabular}{|c|c|c|c|c|c|c|c|}
\hline & & \multicolumn{2}{|c|}{$\begin{array}{l}\text { Group } 1 \\
(1 \mathrm{CC})\end{array}$} & \multicolumn{2}{|c|}{$\begin{array}{l}\text { Group } 2 \\
(6 \text { CCs)* }\end{array}$} & \multicolumn{2}{|c|}{$\begin{array}{c}\text { Group } 3 \\
(12 \text { CCs }) \dagger\end{array}$} \\
\hline & & 0 & No & 0 & No & 0 & No \\
\hline $\begin{array}{l}\text { First } \\
10 \text { Phases }\end{array}$ & $\begin{array}{l}\text { Latency (sec) } \\
\text { Criterion }\end{array}$ & $\begin{array}{l}5 \\
0\end{array}$ & $\begin{array}{l}4 \\
9\end{array}$ & $\begin{array}{l}7 \\
6\end{array}$ & $\begin{array}{l}1 \\
2\end{array}$ & $\begin{array}{l}6 \\
6\end{array}$ & $\begin{array}{l}1 \\
1\end{array}$ \\
\hline $\begin{array}{l}\text { Second } \\
10 \text { Phases }\end{array}$ & $\begin{array}{l}\text { Latency (sec) } \\
\text { Criterion }\end{array}$ & $\begin{array}{l}8 \\
0\end{array}$ & $\begin{array}{l}1 \\
9\end{array}$ & & & & \\
\hline
\end{tabular}

* One rat had to be discarded because CCs were not attained on initial side.

tTwo rats lost electrodes.

Note-Criterion $=$ number of trials to 1,6 , or 12 CCs. 
Table 2

Types of Oscillation

\begin{tabular}{lcccc}
\hline & PO & SO & MO & NO \\
\hline & & Group 1 & $(1 \mathrm{CC})$ & \\
Latency (sec) & 4 & 0 & 1 & 4 \\
Criterion & 0 & 0 & 0 & 9 \\
& & Group 2 & (6 CCs) & \\
Latency (sec) & 3 & 4 & 0 & 1 \\
Criterion & 2 & 4 & 0 & 2 \\
& & Group 3 & & \\
Latency (sec) & 2 & 3 & 12 CCs) & \\
Criterion & 1 & 4 & 1 & 1 \\
\hline
\end{tabular}

Note-PO = primary oscillation, $S O=$ secondary oscillation, $M O$ $=$ mixed oscillation, $N O=$ no oscillation. Criterion $=$ number of trials to 1,6 , or 12 CCs.

Thus, 18 rats oscillated out of the 24 rats which completed the 10 phases. Only 12 rats oscillated in criterion data.

One rat in Group 2 was discarded because of extremely agitated behavior during the stimulation period. A visual examination of the brain using a magnifying lens indicated that the electrode was in the lateral hypothalamus. Two rats in Group 3 were lost when the electrodes came loose.

In latency data there were nine primary oscillators (low values in primary site, high values in secondary site), seven secondary oscillators (high values in primary site, low values in secondary site), and two with both primary and secondary oscillation for a series of at least four consecutive phases each (mixed oscillators) (Table 2). For criterion data there were three primary oscillators, eight secondary oscillators, and one mixed oscillator.

Rats in Group 1 were run for a second set of 10 phases. There were no oscillators in the criterion data (as for the first 10 phases). However, in latency data eight of the nine rats showed oscillation; three rats which had not oscillated during the first 10 phases began to oscillate during the second set of phases. There were five primary oscillators, two secondary oscillators. and one mixed oscillator.

In latericy data the three groups appeared to be similar in number of oscillators. In Group 1, primary oscillation predominated. However, in Groups 2 and 3, secondary oscillation was most frequent. These results for Group 2 are contrary to those obtained in previous experiments (using $6 \mathrm{CCs} /$ phase) in which primary oscillation predominated.

In criterion data no oscillation occurred for the $1 \mathrm{CC}$ group. Almost every rat achieved the $1 \mathrm{CC}$ criterion in one trial after Phases 1 and 2. From Phase 5 through Phase 20, every rat achieved the criterion in one trial. Secondary oscillation was most frequent for rats in Groups 2 and 3 in the criterion measure.

Typical data are provided in Table 3 . The rat in Group 1 shows primary oscillation only in the latency measure. The two other rats show secondary oscillation in both latency and criterion data (except for one phase in the latter for both).

The Group 3 rats, with $12 \mathrm{CC}$ per phase, provided an opportunity to evaluate the trend over that many CCs. The mean latencies for the first and last CCs are shown in Table 4. A number of aspects can be ascertained from this table. (1) There is a decrease from the first to last $\mathrm{CC}$, with the sharpest decrement occurring in Phases 1 and 2. (2) After four to six phases (48 to $72 \mathrm{CCs}$ ), latency is relatively stable. (3) The latency of the last $\mathrm{CC}$ tends to be lower than that for the next $\mathrm{CC}$ in the contralateral side or in the next $\mathrm{CC}$ of the same side.

An evaluation of the latency data for the $6 \mathrm{CC}$ group suggested similar results; however, the decrease from first to last $\mathrm{CC}$, and from first phase to later phases, was not as great, probably because of the lesser number of CCs in each phase. A similar evaluation of duration data for the groups suggested that duration generally varied between 20 and $30 \mathrm{sec}$ and that stable values were attained more quickly (in Phase 1 or 2 ) than were latency data.

Table 3

Typical Oscillation Behavior for One Rat in Each Group

\begin{tabular}{|c|c|c|c|c|c|c|c|c|c|c|}
\hline & 1 & 2 & 3 & 4 & 5 & 6 & 7 & 8 & 9 & 10 \\
\hline & \multicolumn{10}{|c|}{ Group 1 (1 CC, Rat 1) } \\
\hline Latency (sec) & 2 & 7 & 2 & 5 & 3 & 13 & 3 & 18 & 3 & 18 \\
\hline \multirow[t]{2}{*}{ Criterion } & 1 & 1 & 1 & 2 & 1 & 1 & 1 & 1 & 1 & 1 \\
\hline & \multicolumn{10}{|c|}{ Group 2 (6 CCs, Rat 26) } \\
\hline \multirow[t]{2}{*}{$\begin{array}{l}\text { Latency (sec) } \\
\text { Criterion }\end{array}$} & $\begin{array}{l}10.0 \\
21\end{array}$ & $\begin{array}{l}7.0 \\
16\end{array}$ & $\begin{array}{c}12.7 \\
9\end{array}$ & $\begin{array}{l}9.2 \\
9\end{array}$ & $\begin{array}{c}15.2 \\
9\end{array}$ & $\begin{array}{c}10.0 \\
8\end{array}$ & $\begin{array}{l}18.7 \\
12\end{array}$ & $\begin{array}{c}10.5 \\
6\end{array}$ & $\begin{array}{l}22.8 \\
11\end{array}$ & $\begin{array}{l}8.8 \\
6\end{array}$ \\
\hline & \multicolumn{10}{|c|}{ Group 3 (12 CCs, Rat 27) } \\
\hline $\begin{array}{l}\text { Latency (sec) } \\
\text { Criterion }\end{array}$ & $\begin{array}{l}6.6 \\
24\end{array}$ & $\begin{array}{l}5.4 \\
14\end{array}$ & $\begin{array}{l}5.3 \\
12\end{array}$ & $12^{3.3}$ & $\begin{array}{l}6.6 \\
18 \\
\end{array}$ & $\begin{array}{l}3.2 \\
12 \\
\end{array}$ & $\begin{array}{c}7.4 \\
17\end{array}$ & 12.6 & $\begin{array}{c}4.8 \\
17\end{array}$ & 12.0 \\
\hline
\end{tabular}

Note-Criterion $=$ number of trials to 1,6 , or 12 CCs. 
Table 4

Mean Latencies for First and Last CC Trials for Group 3 Rats

\begin{tabular}{lccccc}
\hline & \multicolumn{5}{c}{ Phases } \\
\cline { 2 - 6 } & 1 & 2 & 3 & 4 & 5 \\
CC 1 & 14.1 & 14.3 & 7.9 & 11.9 & 8.6 \\
CC 12 & 4.4 & 5.6 & 6.3 & 6.3 & 8.1 \\
& & & Phases & & \\
\cline { 2 - 6 } & 6 & 7 & 8 & 9 & 10 \\
CC 1 & 11.3 & 6.7 & 6.9 & 7.7 & 7.1 \\
CC 12 & 4.7 & 8.0 & 5.9 & 5.9 & 5.4 \\
\hline
\end{tabular}

\section{DISCUSSION}

These results are consistent with the previous research (Gaito, 1976a, b, c) which demonstrated the oscillation tendency. This tendency seems to be a prominent feature of unilateral sequential alternations and apparently is not due to chance aspects or to poorly placed electrodes in one of the two sites (Gaito, 1976a, b). In the first study (Gaito, 1976a), histological analyses were completed on most of the rats. Oscillation resulted when both electrodes were in the amygdalae or when one was inside and the other was outside the amygdalae. For example, one rat required an extreme number of trials (50) to achieve the criterion of six CCs for the first side stimulated; the electrode was in the caudate putamen/globus pallidus area. Even though this electrode was not in the amygdala and the kindling rate was slow, latency was lower on this side than on the contralateral side and primary oscillation resulted.

In previous research bilateral stimulation produced little effect on the oscillation tendency (Gaito, 1976b). Number of trials per day (one, three, six) also did not disrupt the tendency, although one trial per day may provide the most favorable occasion for it to occur (Gaito, 1976c). Most of the previous research used three trials each day. In the present research, number of CCs per phase also did not seem to interfere with oscillation.

One result which is contrary to that obtained in previous research is the predominance of secondary oscillation for Group 2. Previously, primary oscillation occurred most frequently for the various groups in which six CCs was the criterion used. The basis for this discrepancy is not apparent.

The evaluation of latency and duration changes within and between phases produced results similar to those reported by Burnham (1975) for two phases of kindling. He noted that the duration of seizures at the secondary site was similar to that seen during the last kindling trial with the primary site; latencies, although shorter at the onset of secondary site kindling than at the onset of primary site kindling, slowly decreased. Because of this discrepancy in duration and latency data, Burnham suggested that two mechanisms may be involved in kindling: a con- vulsive mechanism which is fully developed during kindling of the primary site-with duration as an indicator-and a triggering mechanism which is only partially developed during primary site stimulation-latency, its indicator.

As in the previous research, there was again the suggestion that an active inhibitory process is generated during unilateral stimulation which affects that site or the contralateral site during subsequent stimulations. For example, Rat 6 of Group 3 reared on hind paws quickly and began to $\mathrm{CC}$ within a few seconds when stimulating the secondary site. When stimulating the primary site, this rat reared as quickly as when stimulating the secondary site; however, the CC did not result until after at least $6 \mathrm{sec}$ had elapsed. The rat appeared to be actively inhibited during this state of suspension prior to convulsing. Other rats showed different behavior during the inhibition period. For example, Rat 18 of Group 3 performed somewhat similarly to Rat 6. However, at the beginning of the inhibition period, its paws began to show tremors, as if a CC began but ceased within 3 sec. This behavior (abortive CC) was followed by a pause of about $5 \mathrm{sec}$, and then a full $\mathrm{CC}$ appeared. The initial tremors were not recorded as a $C C$ because a duration of at least $5 \mathrm{sec}$ is used as a criterion for a CC.

Thus, two types of behavior were observed during stimulation of the side showing high values during the oscillation process: (1) a complete suspension of behavior followed by a complete convulsion, and (2) an abortive $\mathrm{CC}$, a suspension of behavior, and then a complete convulsion. The latter behavior could obscure the oscillation tendency in some rats because the abortive CC would be recorded as a CC if it persisted for 5 sec or longer. A more complete behavioral analysis is required of the rats' behavior during the oscillation process.

\section{REFERENCES}

Burniam, W. M. Primary and "transfer" seizure development in the kindled rat. Canadian Journal of Neurological Sciences, $1975,2,417-428$.

GArTo, J. An oscillation effect during sequential alternations of unilateral amygdaloid stimulations within the kindling paradigm. Physiological Psychology, 1976, in press. (a)

GArTo, J. The effect of bilateral stimulation during sequential alternation of unilateral amygdaloid stimulation. Bulletin of the Psychonomic Society, 1976, 4, 355-357. (b)

GaITo, J. The effect of number of trials per day during sequential alternation of unilateral amygdaloid stimulation. Bulletin of the Psychonomic Society, 1976, 4, 403-404. (c)

GaITo, J., \& Garto, S. T. Interanimal negative transfer of the kindling effect. Physiological Psychology, 1974, 2, 379-382.

GodDARD, G. V., McINTYRE, D. C., \& LEeCh, C. K. A permanent chance in brain function resulting from daily electrical stimulation. Experimental Neurology, 1969, 25, 295-330.

(Received for publication July 11, 1976.) 